Rev. Bras. Saúde Prod. Anim., Salvador, v.17, n.2, p.237-248 abr./jun., 2016 http://www.rbspa.ufba.br

\title{
Compostagem de resíduos da filetagem de pescado marinho e casca de arroz
}

\author{
Composting of marine fish residues and rice husk
}

\author{
VALENTE, Beatriz Simões ${ }^{1 *}$; XAVIER, Eduardo Gonçalves ${ }^{2}$; PEREIRA, Heron da \\ Silva $^{3}$; PILOTTO, Marcus Vinícius Tabeleão ${ }^{3}$
}

\author{
${ }^{1}$ Universidade Federal de Pelotas, Programa de Pós-Graduação em Zootecnia, Pelotas, Rio Grande \\ do Sul, Brasil. \\ ${ }^{2}$ Universidade Federal de Pelotas, Departamento de Zootecnia, Pelotas, Rio Grande do Sul, Brasil. \\ ${ }^{3}$ Universidade Federal de Pelotas, Pelotas, Rio Grande do Sul, Brasil. \\ *Endereço para correspondência: bsvalente@terra.com.br
}

\section{RESUMO}

Objetivou-se com este estudo avaliar duas proporções de resíduos da filetagem de pescado marinho e casca de arroz na eficiência do processo de compostagem e na qualidade final do composto. Foram comparados dois tratamentos: $\mathrm{T} 1$ - $3 \mathrm{~kg}$ de casca de arroz e $1 \mathrm{~kg}$ de resíduos da filetagem de pescado marinho e $\mathrm{T} 2-3 \mathrm{~kg}$ de casca de arroz e $3 \mathrm{~kg}$ de resíduos da filetagem de pescado marinho. A eficiência do processo de compostagem foi avaliada através das análises de temperatura da biomassa, umidade, cinzas, $\mathrm{pH}$, índice de mineralização do composto, relação carbono/nitrogênio e os teores totais de matéria orgânica, nitrogênio, carbono, fósforo, cálcio, potássio e magnésio. Os dados coletados foram submetidos à análise de variância e regressão e as médias foram comparadas pelo teste de Student Newman Keuls a 5\%. Os resultados demonstraram que a casca de arroz proporcionou compostos imaturos ao final de 90 dias de compostagem, não devendo ser utilizada como agente de estruturação quando o objetivo for produzir fertilizante orgânico. O agente de estruturação pode ser reutilizado um maior número de vezes na compostagem dos resíduos da filetagem de pescado marinho, permitindo que uma maior proporção seja decomposta através da compostagem. O processo de compostagem é uma alternativa tecnológica eficiente para a decomposição dos resíduos da filetagem de pescado marinho.

Palavras-chave: composto, peixe, produção animal, resíduos orgânicos

\section{SUMMARY}

The objective of this study was to evaluate two proportions of marine fish residues and rice hulls on both the efficiency of composting process and the final quality of compost. Two treatments were tested: $\mathrm{T} 1-3 \mathrm{~kg}$ of rice husks and $1 \mathrm{~kg}$ of marine fish residues; and $\mathrm{T} 2-3 \mathrm{~kg}$ of rice husks and $3 \mathrm{~kg}$ of marine fish residues. The following analysis were performed to evaluate the efficiency of the composting process: biomass temperature, moisture, ash, $\mathrm{pH}$, mineralization index of compost, carbon/nitrogen ratio, and the total concentration of organic matter, nitrogen, carbon, phosphorus, calcium, potassium, and magnesium. Data were analyzed through ANOVA and polynomial regression and the averages were compared by SNK test at 5\%. The results showed that rice husks provided immature composts at the end of 90 days of composting. Therefore, they should not be used as a structuring agent if the goal is to producing organic fertilizer. The structuring agent may be reused a larger number of times for composting of residues of marine fish, allowing that a higher proportion suffer decomposition through composting. The composting process is a technological efficient alternative to the decomposition of marine fish residues.

Keywords: animal production, compost, fish, organic residues 
Rev. Bras. Saúde Prod. Anim., Salvador, v.17, n.2, p.237-248 abr./jun., 2016 http://www.rbspa.ufba.br

\section{INTRODUÇÃO}

O Brasil produz aproximadamente 1 milhão e 240 mil toneladas de pescado por ano, sendo que cerca de $45 \%$ dessa produção é oriunda da pesca artesanal (BRASIL, 2015). A região Sul do Rio Grande do Sul contribui expressivamente, garantindo $\mathrm{o}$ fornecimento de diferentes espécies de pescado. É estimado que existam cadastrados cerca de 5.000 pescadores artesanais, sendo a maioria proprietários de embarcações e organizados em colônias (HAIMOVICI et al., 2015). A cadeia produtiva na região é baseada na dependência direta do comércio pesqueiro tradicional de captura, consumo, beneficiamento e comercialização de pescados.

Em decorrência disso, há uma quantidade considerável de pescado presente nas embarcações que não é aproveitada para consumo humano, devido ao seu baixo valor comercial. Aliado a esse fato, o processo de filetagem é uma prática diária, devido à preferência do consumidor pelo filé de peixe, o que acaba aumentando o volume de resíduos gerados. Estima-se que aproximadamente $65 \%$ do peso vivo sejam descartados. Estes resíduos são principalmente vísceras, cauda, coluna vertebral, barbatana, escamas e restos de carne.

Embora grande parte dos resíduos seja destinada à fabricação de farinha, estudos que viabilizem a exploração de outras potencialidades são essenciais para o fortalecimento da cadeia produtiva. Uma alternativa seria a produção de fertilizantes orgânicos a partir dos resíduos de pescado.

Neste sentido, a compostagem torna-se uma importante ferramenta na gestão dos resíduos da cadeia pesqueira. Entretanto, agentes de estruturação necessitam ser misturados aos resíduos proteicos para ajustar o teor de umidade, a relação carbono/nitrogênio e os espaços porosos entre as partículas. A casca de arroz é um abundante resíduo na região Sul do Rio Grande do Sul, que contribui em média com $69 \%$ da produção nacional de arroz, o que resulta em uma produção de mais de 6,8 milhões de toneladas do grão em casca (IRGA, 2016). As cascas representam aproximadamente $23 \%$ da massa do arroz (DELLA et al., 2001) e possuem baixo valor comercial, devido ao seu alto percentual de sílica e fibras como, celulose e hemicelulose (ANGEL et al., 2009). Contudo, é uma importante fonte de $C$ para os micro-organismos envolvidos no processo de compostagem.

O objetivo com este trabalho foi avaliar diferentes proporções de resíduos da filetagem de pescado marinho e casca de arroz na eficiência do processo de compostagem e na qualidade final do composto.

\section{MATERIAL E MÉTODOS}

O estudo foi realizado no Setor de Compostagem do Laboratório de Ensino e Experimentação Zootécnica (LEEZO) Professor Renato Rodrigues Peixoto do Departamento de Zootecnia (DZ) da Faculdade de Agronomia Eliseu Maciel (FAEM) da Universidade Federal de Pelotas (UFPEL) localizado no município de Capão do Leão/RS. O processo de compostagem consistiu de duas etapas. A primeira foi realizada em uma célula de compostagem de alvenaria, impermeabilizada, de 2,20m de comprimento, $1,70 \mathrm{~m}$ de largura e $1,20 \mathrm{~m}$ de altura. A parte superior da célula de compostagem era aberta e protegida por uma estrutura telada e sua 
parte frontal apresentava tábuas móveis para facilitar o preenchimento com os resíduos orgânicos, os quais foram submetidos à compostagem por 60 dias. A segunda etapa, que teve duração de 30 dias, foi realizada em um galpão coberto, com piso impermeabilizado e sem paredes laterais. Foi formada uma pilha de cada tratamento da primeira etapa nas dimensões de $3,00 \mathrm{~m}$ de comprimento, $1,60 \mathrm{~m}$ de largura e $1,00 \mathrm{~m}$ de altura. As células foram abastecidas com resíduos da filetagem de pescado (cabeça, carcaça e vísceras) da atividade pesqueira marítima e casca de arroz. Os resíduos foram obtidos junto ao comércio varejista do Mercado Público do município de Pelotas/RS. A casca de arroz foi adquirida de orizicultores do município.

Em decorrência da dificuldade de se encontrar na literatura pesquisas estudando a utilização de casca de arroz como substrato na compostagem de resíduos de pescado, as proporções entre as matérias primas iniciais foram baseadas em estudos de Liao et al. (1995) e Laos et al. (2002), que usaram serragem e/ou maravalha como agentes de estruturação na compostagem desses resíduos. Portanto, a primeira célula recebeu os resíduos na proporção de $3: 1$, ou seja, para cada $3 \mathrm{~kg}$ de casca de arroz foi adicionado $1 \mathrm{~kg}$ de resíduos da filetagem de pescado marinho (T1). Na outra célula a proporção utilizada foi $3: 3$, ou seja, para cada $3 \mathrm{~kg}$ de casca de arroz foram usados $3 \mathrm{~kg}$ de resíduos da filetagem de pescado marinho (T2). A altura utilizada para as camadas de casca de arroz foi de $0,15 \mathrm{~m}$, seguindo a metodologia de Paiva (2004), determinada pelas pesagens e definida por medições com auxílio de uma fita métrica. A massa de casca de arroz por camada foi de $88,5 \mathrm{~kg}$. As porções de resíduos de peixe foram dispostas sobre as camadas de casca de arroz, respeitando a distância de $0,10 \mathrm{~m}$ entre elas, das paredes e da parte frontal da célula de compostagem. Assim, em cada camada de $0,15 \mathrm{~m}$ de casca de arroz foi disposto $29,5 \mathrm{~kg}$ (T1) e $88,5 \mathrm{~kg}$ (T2) de resíduos de pescado marinho respectivamente. Os resíduos orgânicos ocuparam a altura de $1 \mathrm{~m}$. A água foi adicionada com o auxílio de um recipiente graduado, na proporção de $30 \%$ da massa da camada de casca de arroz (COSTA et al., 2005), correspondendo a $26 \mathrm{~L}$ por camada.

Ao final do período de 60 dias de compostagem, a biomassa foi retirada e pesada para posterior cálculo do volume de água a ser adicionada durante a segunda etapa. A quantidade de massa foi de $491 \mathrm{~kg}$ e $377 \mathrm{~kg}$ para o $\mathrm{T} 1 \mathrm{e} \mathrm{T} 2$, respectivamente. $\mathrm{O}$ volume de água foi calculado com base em $30 \%$ do total de biomassa. Assim, foi adicionado 148L de água para o T1 e $114 \mathrm{~L}$ para o T2, durante o revolvimento das pilhas a cada 15 dias.

Foram colocadas cinco estacas de madeira numeradas a fim de demarcar cada ponto de coleta e de aferição. As avaliações da temperatura da massa em compostagem foram realizadas em dois períodos do dia, às 9:00 e 16:00 h, utilizando-se um termômetro digital $( \pm$ $0,5^{\circ} \mathrm{C}$ COTERM 180) com haste de $0,17 \mathrm{~m}$. A temperatura ambiente média diária foi obtida na Estação Agroclimatológica de Pelotas, localizada $31^{\circ} 52^{\prime} 00^{\prime \prime}$ Sul e 52 $21^{\prime} 24^{\prime \prime}$ Oeste, a uma altitude de 13,24 m. As análises da composição química da biomassa foram realizadas em triplicata, sendo que a primeira amostragem correspondeu aos substratos casca de arroz e peixe marinho..

No Laboratório de Nutrição Animal do DZ/FAEM/UFPEL foi realizada a determinação da umidade, $\mathrm{pH}$, nitrogênio total, segundo metodologia descrita por Silva \& Queiroz (2004) e 
Rev. Bras. Saúde Prod. Anim., Salvador, v.17, n.2, p.237-248 abr./jun., 2016 http://www.rbspa.ufba.br ISSN 15199940

também para a análise da matéria orgânica total, teor de cinzas e do carbono orgânico total, conforme metodologia descrita por Kiehl (1985). A relação $\mathrm{C} / \mathrm{N}$ foi obtida pela equação $\mathrm{C} / \mathrm{N}$ $=\% \mathrm{C} \div \% \mathrm{~N}$, "onde $\% \mathrm{C}=$ porcentagem de carbono orgânico total na amostra; $\% \mathrm{~N}=$ porcentagem de nitrogênio total na amostra, conforme descrito por Tedesco et al. (1995). O cálculo do índice de mineralização do composto foi obtido através da equação IMC $=\% \mathrm{CZ} \div \% \mathrm{C}$, "onde $\% \mathrm{CZ}=$ porcentagem de cinzas na amostra; $\% \mathrm{C}=$ porcentagem de carbono orgânico total na amostra, segundo Drozd et al. (1997). No Laboratório de Química do Solo do Departamento de Solos da FAEM/UFPEL foram analisados os teores totais de fósforo, magnésio, cálcio e potássio a partir da metodologia descrita por Tedesco et al. (1995).

As demais coletas foram realizadas nos pontos demarcados, nos seguintes períodos: 30 e 60 dias da primeira etapa e aos 30 dias da segunda etapa de compostagem.

Para a análise estatística, utilizou-se o delineamento completamente casualizado. Os dados coletados foram submetidos à análise de variância pelo procedimento GLM ("General Linear Models") do programa "Statistical Analysis System" versão 9.1 (SAS, 2003) e regressão polinomial, sendo as médias comparadas pelo teste de Student Newman Keuls a um nível de significância de 5\%.

\section{RESULTADOS E DISCUSSÃO}

Na Figura 1, pode ser observado no dia zero que a média da temperatura da biomassa foi de $20,5^{\circ} \mathrm{C}$ para o $\mathrm{T} 1 \mathrm{e}$ $18,7^{\circ} \mathrm{C}$ para o $\mathrm{T} 2$, caracterizando assim a fase criófila do processo de compostagem (KIEHL, 1985). A partir deste período, houve um aumento da temperatura em ambos os tratamentos atingindo aos 30 dias de compostagem, valores de $34,8^{\circ} \mathrm{C}$ e $38,1^{\circ} \mathrm{C}$ para, respectivamente, o $\mathrm{T} 1$ e o $\mathrm{T} 2$. Estas verificações demonstram uma longa fase mesófila, possivelmente em decorrência do maior conteúdo de nitrogênio inicial (9\%) (Tabela 1) prontamente disponível nas carcaças de pescado, para a síntese de proteínas microbianas e, também, pelo carbono facilmente degradável. Adicionalmente, Bernal et al. (2009) salientam que as bactérias e os fungos mesófilos degradam componentes simples da matéria orgânica, como açúcares, aminoácidos e proteínas, aumentando rapidamente a temperatura. Concomitantemente, os microorganismos utilizam o carbono solúvel e facilmente degradável como fonte de energia, sendo uma pequena fração incorporada às células microbianas (TUOMELA et al., 2000). O restante do carbono é liberado na forma de $\mathrm{CO}_{2}$, ficando o calor retido no interior da massa em compostagem, devido ao metabolismo microbiano ser exotérmico (TANG et al., 2004).

De outra forma, foi constatado no decorrer dos 60 dias do processo, decréscimos da temperatura da biomassa em ambas as proporções (26,8 e $29,7^{\circ} \mathrm{C}$ ), persistindo até os 90 dias de compostagem $\left(26,4\right.$ e $\left.26,7^{\circ} \mathrm{C}\right)$, respectivamente, para os tratamentos $\mathrm{T} 1$ e T2, atingindo temperaturas próximas a do ambiente $\left(25,1^{\circ} \mathrm{C}\right)$. No $\mathrm{T} 1$ os dados não permitiram ajuste de equação de regressão, porém o T2 apresentou uma resposta quadrática para $\mathrm{o}$ comportamento das médias da temperatura da biomassa $\left(\mathrm{R}^{2}=0,72\right)$. Sanes et al. (2015) estudaram a compostagem de uma maior proporção de resíduos de pescado em relação à casca de arroz (3:1) e verificaram que 
Rev. Bras. Saúde Prod. Anim., Salvador, v.17, n.2, p.237-248 abr./jun., 2016 http://www.rbspa.ufba.br ISSN 15199940

aos 70 dias de compostagem a temperatura da biomassa $\left(25^{\circ} \mathrm{C}\right)$ esteve próxima à temperatura ambiente, concluindo que $o$ processo de compostagem estaria entrando na fase de maturação (Figura 1).

Tabela 1. Composição química dos substratos utilizados na compostagem

\begin{tabular}{lcc}
\hline Composição & Casca de arroz & Peixe Marinho \\
\hline $\mathrm{pH}$ & $7,4 \pm 0,85$ & $\mathrm{nd}$ \\
Umidade (\%) & $16,1 \pm 1,20$ & $80,3 \pm 0,90$ \\
Matéria orgânica total (\%) & $80,7 \pm 1,02$ & $90,4 \pm 1,50$ \\
Cinzas (\%) & $19,3 \pm 0,50$ & $9,6 \pm 0,90$ \\
Carbono orgânico total (\%) & $44,8 \pm 0,70$ & $50,2 \pm 1,01$ \\
Nitrogênio total (\%) & $0,6 \pm 0,01$ & $9,0 \pm 0,05$ \\
Relação carbono/nitrogênio & $74,7 \pm 0,90$ & $5,6 \pm 0,06$ \\
Fósforo $\left(\mathrm{g} \mathrm{kg}^{-1}\right)$ & $0,8 \pm 0,20$ & $18,1 \pm 1,08$ \\
Potássio $\left(\mathrm{g} \mathrm{kg}^{-1}\right)$ & $4,8 \pm 0,30$ & $9,4 \pm 0,09$ \\
Cálcio $\left(\mathrm{g} \mathrm{kg}^{-1}\right)$ & $2,2 \pm 0,02$ & $35,5 \pm 1,50$ \\
Magnésio $\left(\mathrm{g} \mathrm{kg}^{-1}\right)$ & $0,4 \pm 0,01$ & $1,1 \pm 0,01$ \\
\hline
\end{tabular}

Valores médios de três replicatas. $n d=$ não determinado.

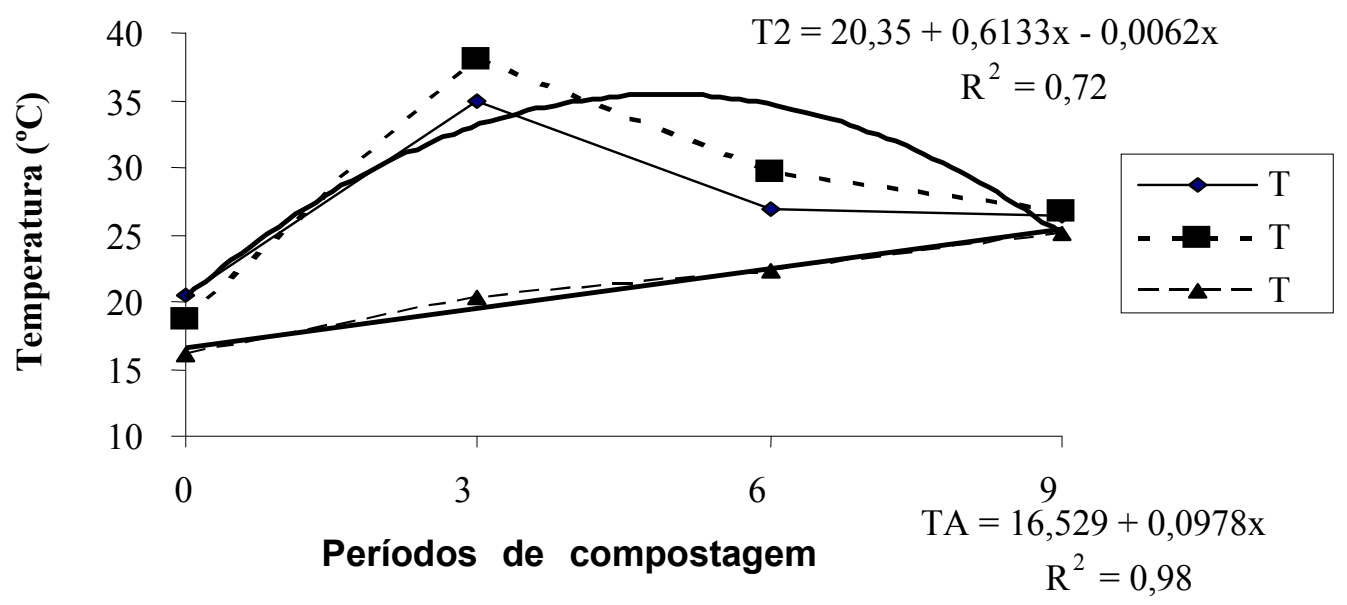

Figura 1. Médias da temperatura da biomassa e do ambiente durante a compostagem de diferentes proporções de resíduos da filetagem de pescado e casca de arroz. T1: casca de arroz + resíduos de peixe marinho (3:1); T2: casca de arroz + resíduos de peixe marinho (3:3); TA: temperatura ambiente do ar

Com base na linearidade do modelo de equação e no seu elevado coeficiente de determinação $\left(\mathrm{R}^{2}=0,98\right)$ constatou-se que a temperatura ambiente do ar não teve influência na temperatura da biomassa no $\mathrm{T} 2$, que apresentou um comportamento quadrático. A parte externa dos materiais compostados funcionou como uma massa protetora, permitindo que o calor produzido pela atividade microbiana fosse retido pelas partículas dos substratos, o que também 
acarretou uma menor perda de umidade no decorrer do T2 (Tabela 2). Valente et al. (2011) trabalhando com a compostagem da mistura de dejetos de bovinos leiteiros e cama de aviário e/ou maravalha verificaram que o comportamento linear da temperatura da biomassa dos tratamentos testados não acompanhou as oscilações da temperatura ambiente do ar.

A evolução da temperatura da biomassa em ambos os tratamentos demonstrou que a população mesofílica manteve-se presente em todo o período experimental. Este fato sugere que a alta relação carbono/nitrogênio inicial $(74,7 / 1)$ do agente de estruturação e também da biomassa no decorrer dos períodos (Tabela 2), associado ao tipo de carbono da casca de arroz afetaram o desenvolvimento dos micro-organismos termófilos. Leconte et al. (2009) estudando a compostagem da mistura de casca de arroz e excretas de aves nas proporções $1: 1$ e $2: 1$, verificaram que a alta relação carbono/nitrogênio (109/1), o baixo carbono solúvel em água $(3,1 \mathrm{~g} / \mathrm{kg})$, a presença de $59 \%$ de celulose, de $12,1 \%$ de hemicelulose e de $20,9 \%$ de lignina na casca de arroz afetaram a fase termófila do processo de compostagem. Outra característica importante da casca de arroz, ressaltada por Carmona et al. (2013), é a sua superfície revestida e o alto teor de sílica que reduz a capacidade de retenção de água, podendo limitar o ataque microbiano. Corroborando com os autores, Caldeira et al. (2012) utilizaram casca de arroz como agente de estruturação na compostagem de resíduos do abate de frangos $\mathrm{e}$ verificaram que as temperaturas durante o período de 130 dias não ultrapassaram os $43^{\circ} \mathrm{C}$, sendo atribuído à atividade microbiana reduzida na biomassa, que foi afetada pela baixa degradabilidade e pela menor capacidade de retenção de água. Pesquisadores ressaltam que a proporção de agente de estruturação depende diretamente de suas propriedades físico-químicas (LIAO et al., 1995; RUGGIERI et al., 2012).

Foram observados acréscimos nos teores de matéria orgânica total e carbono total aos 60 dias de compostagem para ambos os tratamentos (Tabela 2). Os valores obtidos indicam a morte de parte da microflora e também uma menor atividade microbiana no meio, podendo ser constatado pelos decréscimos na temperatura média da biomassa no período, que chegou próxima à temperatura ambiente (Figura 1). Os resultados concordam com Zhu (2007), que afirma que valores mais elevados de relação carbono/nitrogênio significam que não há nitrogênio suficiente para um ótimo crescimento das populações microbianas, havendo imobilização de nitrogênio pelos micro-organismos, prejudicando assim a velocidade de decomposição dos resíduos orgânicos, que será reduzida. Outro fato a ser considerado é que a capacidade dos micro-organismos em assimilar a matéria orgânica está diretamente relacionada à sua habilidade em produzir enzimas necessárias para a degradação dos substratos (TUOMELA et al., 2000).

Por outro lado, pode ser constatado que houve uma redução do teor de nitrogênio total no mesmo período, devido a sua utilização por parte das populações microbianas e também em decorrência da volatilização da amônia. Adicionalmente, Liang et al. (2004) ressaltam que a volatilização do nitrogênio na forma de amônia pode concorrer com a sua imobilização pelos micro-organismos, particularmente quando a relação carbono/nitrogênio da mistura é alta e também na presença de carbono recalcitrante, como a lignina (LECONTE et al., 2009). Concomitantemente, a amônia produzida 
Rev. Bras. Saúde Prod. Anim., Salvador, v.17, n.2, p.237-248 abr./jun., 2016 http://www.rbspa.ufba.br ISSN 15199940

pode inibir a atividade microbiana (EL KADER et al., 2007), o que também explica as reduções da temperatura média da biomassa nos tratamentos $\mathrm{T} 1$ $\left(26,8^{\circ} \mathrm{C}\right)$ e $\mathrm{T} 2\left(29,7^{\circ} \mathrm{C}\right)$ aos 60 dias de compostagem. Também foi observado no presente estudo que a relação carbono/nitrogênio do T1 foi significativamente superior a do $\mathrm{T} 2$ $(\mathrm{P}<0,05)$, devido à atividade metabólica microbiana reduzida aos 60 dias de compostagem e a maior proporção de casca de arroz em relação ao resíduo de pescado (3:1).

Tabela 2. Teores médios, desvios padrão e coeficientes de variação da composição química durante a compostagem de resíduos de pescado marinho e casca de arroz

\begin{tabular}{|c|c|c|c|c|c|c|c|}
\hline \multirow{2}{*}{ Composição } & \multicolumn{3}{|c|}{ T1 } & \multicolumn{3}{|c|}{$\mathrm{T} 2$} & \multirow{2}{*}{$\mathrm{IN}-25$} \\
\hline & 30 & 60 & 90 & 30 & 60 & 90 & \\
\hline UMID (\%) & $22,5 \pm 3,31$ & $18,6 \pm 0,85$ & $28,1 \pm 3,48$ & $26,4 \pm 5,28$ & $28,6 \pm 10,91$ & $32,9 \pm 1,71$ & $\leq 50 \%$ \\
\hline CV (\%) & 15 & 5 & 12 & 20 & 38 & 5 & \\
\hline $\mathrm{pH}$ & $8,1 \pm 0,39$ & $7,8 \pm 0,50$ & $7,3 \pm 0,60$ & $8,3 \pm 0,42$ & $8,10,25 \pm$ & $7,6 \pm 0,19$ & $\geq 6,0$ \\
\hline CV (\%) & 5 & 6 & 9 & 5 & 3 & 2 & \\
\hline MO (\%) & $79,2 \pm 1,41$ & $81,0 \pm 0,37$ & $79,9 \pm 0,81$ & $79,4 \pm 1,42$ & $82,6 \pm 4,03$ & $78,0 \pm 0,84$ & $\geq 40 \%$ \\
\hline CV (\%) & 2 & 0,5 & 1 & 2 & 5 & 1 & \\
\hline $\mathrm{CZ}(\%)$ & $20,8 \pm 1,42$ & $19,0 \pm 0,37$ & $20,1 \pm 0,81$ & $20,6 \pm 1,42$ & $17,4 \pm 4,04$ & $22,0 \pm 0,84$ & \\
\hline CV $(\%)$ & 7 & 2 & 4 & 7 & 23 & 4 & \\
\hline $\mathrm{C}(\%)$ & $44,0 \pm 0,79$ & $45,0 \pm 0,20$ & $44,4 \pm 0,45$ & $44,1 \pm 0,79$ & $45,9 \pm 2,24$ & $43,4 \pm 0,47$ & $\geq 15 \%$ \\
\hline $\mathrm{CV}(\%)$ & 2 & 0,4 & 1 & 2 & 5 & 1 & \\
\hline N (\%) & $1,3 \pm 0,40$ & $0,5 \pm 0,08$ & $0,8 \pm 0,08$ & $1,7 \pm 1,15$ & $0,9 \pm 0,17$ & $1,1 \pm 0,11$ & $\geq 0,5 \%$ \\
\hline $\mathrm{CV}(\%)$ & 30 & 15 & 10 & 67 & 19 & 10 & \\
\hline$C: N$ & $37,1 \pm 12,93$ & $84,0 \pm 12,05^{\mathrm{A}}$ & $54,2 \pm 5,8$ & $39,1 \pm 24,70$ & $55,3 \pm 0,13^{\mathrm{B}}$ & $39,4 \pm 4,0$ & $\leq 20$ \\
\hline CV (\%) & 35 & 14 & 11 & 63 & 16 & 10 & \\
\hline IMC & $0,5 \pm 0,04$ & $0,4 \pm 0,01$ & $0,5 \pm 0,02$ & $0,5 \pm 0,04$ & $0,4 \pm 0,10$ & $0,5 \pm 0,02$ & \\
\hline CV (\%) & 9 & 2 & 5 & 9 & 26 & 5 & \\
\hline
\end{tabular}

Médias seguidas de letras maiúsculas diferentes, no mesmo período, diferem entre si pelo teste de Student Newman Keuls a 5\%.

$\mathrm{T} 1=$ casca de arroz + resíduos de peixe marinho (3:1); T2= casca de arroz + resíduos de peixe marinho (3:3); $\mathrm{UMID}=$ umidade; $\mathrm{MO}=$ matéria orgânica total; $\mathrm{CZ}=$ cinzas; $\mathrm{C}=$ carbono orgânico total; $\mathrm{N}=$ nitrogênio total; $\mathrm{C} / \mathrm{N}=$ relação carbono/nitrogênio; $\mathrm{IMC}=$ índice de mineralização do composto.

*Instrução Normativa n²5/2009 (BRASIL, 2011).

Contrariamente, aos 90 dias de compostagem, ocorreram reduções nos teores de matéria orgânica total e carbono total em ambos os tratamentos, devido à oxidação da matéria orgânica pelos micro-organismos, que liberam $\mathrm{CO}_{2}$ através da sua respiração (ZHANG \&
HE, 2006), diminuindo assim a concentração de carbono. Os revolvimentos a cada 15 dias possivelmente tenham provido a oxidação da matéria orgânica devido à incorporação de oxigênio na biomassa. Contudo, este procedimento não foi 
suficiente para elevar a temperatura da biomassa, podendo estar relacionado à ausência de nitrogênio total dos resíduos da filetagem de pescado, que haviam sido completamente degradados aos 60 dias de compostagem. Portanto, os acréscimos nos teores de nitrogênio total, tanto no $\mathrm{T} 1$ $(0,8 \pm 0,08 \%)$ quanto no $\mathrm{T} 2(1,11 \pm$ $0,11 \%)$, podem ser explicados pela morte de parte dos micro-organismos mesófilos, que incorporam e imobilizam o nitrogênio no seu protoplasma celular (CAYUELA et al., 2009), podendo ser confirmado na Figura 1, onde se verifica uma redução da temperatura da biomassa. Outro aspecto diz respeito ao $\mathrm{pH}$ alcalino da biomassa aos 30 dias de compostagem, sendo verificado reduções nos períodos subsequentes em ambas as proporções estudadas, que foi proporcionada pela atividade metabólica dos microorganismos nos substratos. O tipo de carboidrato presente na casca de arroz, como celulose, hemicelulose e lignina diminui o $\mathrm{pH}$ pela produção de metabólitos ácidos e $\mathrm{CO}_{2}$ (LECONTE et al., 2009). Diferentemente, aos 60 dias de compostagem, a possível volatilização de amônia pode ter provocado uma dissociação do íon amônio, uma vez que a sua oxidação a nitrato libera $2 \mathrm{H}^{+}$, reduzindo assim o $\mathrm{pH}$ do meio. Esse processo é mediado por bactérias nitrificantes que são ativadas em temperaturas mesófilas (LECONTE et al., 2009).

Os resultados obtidos para o índice de mineralização do composto foram inferiores aos preconizados por Drozd et al. (1997), que afirmam que quanto mais alto for o índice $(>1,30)$, maior terá sido a mineralização da matéria orgânica total. Além disso, pode-se observar que os baixos valores do índice de mineralização do composto mantiveram-se praticamente constantes no decorrer do estudo, variando de 0,1 a 0,2 , demonstrando uma menor oxidação da matéria orgânica, que está diretamente relacionada à redução da liberação de $\mathrm{CO}_{2}$ pela atividade respiratória dos micro-organismos, sugerindo que o tipo de carbono presente na casca de arroz e a alta relação carbono/nitrogênio afetaram a velocidade de mineralização da biomassa. Corroborando com os resultados, verificou-se que a casca de arroz apresentou estrutura inicial intacta ao final dos 90 dias de compostagem, demonstrando-se assim resistente à degradação microbiana, devido ao seu alto conteúdo de sílica e lignina (LECONTE et al., 2009). As observações a campo concordam com Sanes et al. (2015), que verificaram partículas intactas de casca de arroz em um tempo menor de compostagem (70 dias). A estrutura intacta da casca de arroz ao final do processo associada à rápida decomposição dos resíduos da filetagem de pescado e à alta relação carbono/nitrogênio no decorrer dos 90 dias de compostagem sugerem que uma maior proporção de fonte proteica poderia ter sido utilizada.

$\mathrm{Na}$ Tabela 3, aos 60 dias de compostagem, podem ser observados teores totais reduzidos de fósforo, cálcio e magnésio em ambos os tratamentos. Os resultados sugerem que o $\mathrm{pH}$ alcalino favoreceu a adsorção do fósforo às moléculas de cálcio e magnésio, causando sua indisponibilidade temporária, concordando com Tumuhairwe et al. (2009) que verificaram reduções no teor de fósforo durante a compostagem da mistura de resíduos de vegetais $\mathrm{e}$ atribuíram tal fato a pouca mobilidade desse macromineral e à formação de complexos insolúveis com o cálcio e o magnésio da matéria orgânica em $\mathrm{pH}$ alcalino. Diferentemente, aos 90 dias de compostagem, verificou-se que o teor de fósforo total no $\mathrm{T} 2\left(6,9 \pm 1,01 \mathrm{~g} \mathrm{~kg}^{-1}\right)$ foi mais elevado do que no T1 $(3,2 \pm 0,54 \mathrm{~g}$ $\left.\mathrm{kg}^{-1}\right)$. Embora não tenha sido realizada 
Rev. Bras. Saúde Prod. Anim., Salvador, v.17, n.2, p.237-248 abr./jun., 2016 http://www.rbspa.ufba.br ISSN 15199940

análise da composição química da mistura dos substratos iniciais, o valor indica que a maior proporção (3:3) de resíduos de pescado utilizada possa ter influenciado a alta concentração do fósforo total.

Pesquisadores afirmam que com a mineralização da matéria orgânica haverá um incremento no teor de cinzas do composto final (RASHAD et al., 2010). Entretanto, cabe lembrar que o índice de mineralização do composto manteve-se constantemente inferior durante os 90 dias de compostagem.
Portanto, o aumento na concentração de fósforo total pode ser atribuído ao fósforo solúvel imobilizado pelas células microbianas, que promoveram o aumento de fósforo orgânico no produto final. De modo semelhante, Rashad et al. (2010) estudando a compostagem da mistura de palha de arroz e resíduos agroindustriais verificaram que $o$ fósforo total aumentou para todos os tratamentos, devido a maior solubilização de fósforo que foi imobilizado pelas células microbianas.

Tabela 3. Teores médios, desvios padrão e coeficientes de variação da composição mineral durante a compostagem de resíduos de pescado marinho e casca de arroz

\begin{tabular}{|c|c|c|c|c|c|c|c|}
\hline \multirow{2}{*}{$\begin{array}{l}\text { Composição } \\
\text { mineral }\left(\mathrm{g} \mathrm{kg}^{-1}\right)\end{array}$} & \multicolumn{3}{|c|}{$\mathrm{T} 1$} & \multicolumn{3}{|c|}{$\mathrm{T} 2$} & \multirow{2}{*}{$\mathrm{IN}-25^{* *}$} \\
\hline & 30 & 60 & 90 & 30 & 60 & 90 & \\
\hline Fósforo & $5,4 \pm 1,78$ & $0,4 \pm 0,03$ & $3,2 \pm 0,54$ & $5,8 \pm 2,55$ & $2,4 \pm 0,34$ & $6,9 \pm 1,01$ & $* \mathrm{~cd}$ \\
\hline CV (\%) & 33 & 8 & 17 & 44 & 14 & 15 & \\
\hline Potássio & $3,0 \pm 0,05$ & $3,0 \pm 0,05$ & $3,2 \pm 0,38$ & $2,9 \pm 0,33$ & $2,9 \pm 0,26$ & $3,4 \pm 0,35$ & $*_{\mathrm{cd}}$ \\
\hline CV (\%) & 2 & 2 & 12 & 11 & 9 & 11 & \\
\hline Cálcio & $15,9 \pm 4,04$ & $1,6 \pm 0,41$ & $3,9 \pm 0,64$ & $20,1 \pm 7,21$ & $3,4 \pm 0,45$ & $12,8 \pm 2,24$ & $\geq 1 \%$ \\
\hline CV (\%) & 25 & 25 & 17 & 36 & 13 & 17 & \\
\hline Magnésio & $0,7 \pm 0,12$ & $0,4 \pm 0,11$ & $0,4 \pm 0,06$ & $0,7 \pm 0,25$ & $0,4 \pm 0,05$ & $0,9 \pm 0,12$ & $\geq 1 \%$ \\
\hline CV $(\%)$ & 17 & 26 & 13 & 35 & 12 & 13 & \\
\hline
\end{tabular}

Da mesma forma, valores mais altos para os teores de potássio, cálcio e magnésio no $\mathrm{T} 2$ foram encontrados ao final do período, os quais corresponderam a $3,4 \pm 0,35 \mathrm{gkg}^{-1}, 12,8$ $\pm 2,24 \mathrm{gkg}^{-1}$ e $0,9 \pm 0,12 \mathrm{gkg}^{-1}$ respectivamente. A liberação do cálcio e do magnésio é fortemente influenciada pelas concentrações de lignina e fenólicos solúveis, porque a capacidade de troca catiônica da matéria orgânica tem sua origem nas cargas negativas oriundas dos grupos carboxílicos e fenólicos (KIEHL, 1985).
Considerando os compostos produzidos, pode ser verificado nas Tabelas 2 e 3 que os valores de relação carbono/nitrogênio estão acima do recomendado pela $\mathrm{IN}$ $25 / 2009$, enquanto que a concentração de magnésio manteve-se abaixo, não sendo recomendada a sua utilização como fertilizante orgânico simples, segundo as normas do Ministério da Agricultura, Pecuária e Abastecimento do Brasil.

Esse estudo mostra que o processo de compostagem é uma alternativa tecnológica eficiente para a decomposição dos resíduos da filetagem 
Rev. Bras. Saúde Prod. Anim., Salvador, v.17, n.2, p.237-248 abr./jun., 2016 http://www.rbspa.ufba.br ISSN 15199940

de pescado marinho. A casca de arroz proporciona compostos imaturos ao final de 90 dias de compostagem e não deve ser utilizada como agente de estruturação quando o objetivo for produzir fertilizante orgânico. Contudo, a casca de arroz pode ser utilizada um maior número de vezes como fonte de carbono, sendo que suas características químicas permitem que uma maior proporção de resíduos da filetagem de pescado seja decomposta através da compostagem.

\section{REFERÊNCIAS}

ANGEL, J.D.M.; VÁSQUEZ, T.G.P.; JUNKES, J.A., HOTZA, D.

Caracterização de cinza obtida por combustão de casca de arroz em reator de leito fluidizado. Química nova, v.32, n.5, p. 1110-1114, 2009.

\section{BRASIL. Ministério da Agricultura, Pecuária e Abastecimento. Instrução Normativa $\mathbf{n}^{\circ} 25$, de 23 de julho de 2009. Dispõe sobre as especificações e as garantias, as tolerâncias, o registro, a embalagem e a rotulagem dos fertilizantes orgânicos simples, mistos, compostos, organominerais e biofertilizantes destinados à agricultura. Disponível em: $<$ www.agricultura.gov.br $>$. Acessado em: 4 fev. 2011.}

\section{BRASIL. Ministério da Pesca e} Aquicultura. Disponível em: $<$ http://www.mpa.gov.br $>$. Acesso em: 29 jul. 2015.

BERNAL, M.P.; ALBURQUERQUE, J.A.; MORAL, R. Composting of animal manures and chemical criteria for compost maturity assessment. A review. Bioresource Technology, v.100, p.5444-5453, 2009.
CALDEIRA, M.V.W. HARBS, R.M.P.; TAVARES, L.B.B.; SPERANDIO, V.; PILON, L.C. Maturidade de composto orgânico de resíduos do abatedouro de frangos. Revista Verde de Agroecologia e Desenvolvimento Sustentável, v.7, n.2, p.149-155, 2012.

CARMONA, V.B.; OLIVEIRA, R.M, SILVA, W.T.L.; MATTOSO, L.H.C; MARCONCINI, J.M. Nanosilica from rice husk: extraction and characterization.

Industrial Crops and Products, v.43, p.291-296, 2013.

CAYUELA, M.L.; MONDINI C.; INSAM, H.; SINICCO, T.; FRANKEWHITTLE, I. Plant and animal wastes composting: effects of the $\mathrm{N}$ source on process performance. Bioresource Technology, v.100, p.3097-3106, 2009.

COSTA, M.S.S.DE.M.; COSTA, L.A.DE.M.; OLIBONE, D.; RÖDER, C.; BURIN, A.; KAUFMANN, A.V.; ORTOLAN, M.L. Efeito da aeração no primeiro estágio da compostagem de carcaça de aves. Engenharia Agrícola, v.25, n.2, p.549-556, 2005.

DELLA, V.P.; KÜHN, I., HOZTA, D. Caracterização de cinza de casca de arroz para uso como matéria-prima na fabricação de refratários de sílica. Química Nova, v.24, n.6, p.778-782, 2001.

DROZD, J.; JAMROZ, E.; LICZNAR, M.; LICZNAR, S.E.; WEBER, J. Organic matter transformation and humic indices of compost maturity satage during composting of municipal solid wastes. Grunwaldzka, v.53, p.855-861, 1997.

EL KADER, N.A.; ROBIN, P.; PAILLAT, J.M.; LETERME, P. Turning, compacting and the addition of water as factors affecting gaseous emissions in farm manure composting. Bioresource Technology, v.98, p.2619-2628, 2007. 
Rev. Bras. Saúde Prod. Anim., Salvador, v.17, n.2, p.237-248 abr./jun., 2016 http://www.rbspa.ufba.br ISSN 15199940

HAIMOVICI, M.; VASCONCELLOS, M.; KALIKOSKI, D. C.; ABDALAH, P.; CASTELLO, J. P.;

HELLEBRANDT, D. Diagnóstico da pesca no litoral do estado do Rio Grande do Sul. Disponível em: $\leq$ http://www.researchgate.net/publicatio n/268286804>. Acesso em: 29 jul 2015.

\section{INSTITUTO RIO GRANDENSE DO}

ARROZ. Série histórica de produção e produtividade - RS x BR. Disponível em:

$<$ http://www.irga.rs.gov.br/upload/20150 720134318producao_rs_e_brasil.pdf $>$ Acesso em: 23 abr. $201 \overline{6}$.

KIEHL, E.J. Fertilizantes orgânicos. Piracicaba: Agronômica Ceres Ltda, 1985. $492 \mathrm{p}$.

LAOS, F.; MAZZARINO, M.J.; WALTER, I.; ROSELLI, L.; SATTI, P.; MOYANO, S. Composting of fish offal and biosolids in Northwestern Patagonia. Bioresource Technology, v.81, p.179186, 2002.

LECONTE, M.C.; MAZZARINO, M.J.; SATTI, P.; IGLESIAS, M.C.; LAOS, F. Co-composting rice hulls and/or sawdust with poultry manure in NE Argentina. Waste Management, v.29, p.24462453, 2009.

LIAO, P.H.; MAY, A.C.; CHIENG, S.T. Monitoring process efficiency of a full-scale in-vessel system for composting fisheries wastes.

Bioresource Technology, v.54, p.159163, 1995.

LIANG, Y.; LEONARD, J.J.; FEDDES, J.J.R.; MCGILL, W.B. A mathematical model of ammonia volatization in composting. Transactions of the ASAE, v.47, n.5, p.1667-1680, 2004.
PAIVA, D.P. de. Uso da compostagem como destino de suínos mortos e restos de parição. In: Tecnologias para o manejo de resíduos na produção de suínos: manual de boas práticas. Concórdia: Embrapa Suínos e Aves, 2004. p.100-104.

RASHAD, F.M.; SALEH, W.D.; MOSELHY, M.A. Bioconversion of rice straw and certain agro-industrial wastes to amendments for organic farming system: 1 . Composting, quality, stability and maturity indices.

Bioresource Technology, v.101, p.5952-5960, 2010.

RUGGIERI, L.; GEA, T.; ARTOLA, A.; SANCHEZ, A. A study on air filled porosity evolution in sludge composting. International Journal of Environment and Waste Management, v.9, n.1, p.56-58, 2012.

SANES, F.S.M.; STRASSBURGER, A.S.; ARAÚJO, F.B.; MEDEIROS, C.A.B. Compostagem e fermentação de resíduos de pescado para produção de fertilizantes orgânicos. Semina: Ciências Agrárias, v.36, n.3, p.12411252, 2015.

SAS Institute. Statistical analysis system. Release 9.1. (Software). Cary, 2003.

SILVA, D.J.; QUEIROZ A.C. de. Análise de Alimentos: métodos Químicos e Biológicos. Viçosa: Universidade Federal de Viçosa, 2004. $235 p$.

TANG, J.C.; KANAMORI, T.; INQUE, $\mathrm{Y}$. Changes in the microbial community structure during thermophilic composting of manure as detected by quinone profile method. Process Biochemistry, v.39, p.1999-2006, 2004. 
Rev. Bras. Saúde Prod. Anim., Salvador, v.17, n.2, p.237-248 abr./jun., 2016 http://www.rbspa.ufba.br ISSN 15199940

TEDESCO, M.J.; GIANELLO, C.;

BISSANI, C.A.; BOHNEN, H.;

VOLKWWEISS, S.J. Análises de solo, plantas e outros materiais. Porto

Alegre: Universidade Federal do Rio

Grande do Sul. 1995. 174p. (Boletim

Técnico de Solos, 5)

TUMUHAIRWE, J.B.; TENYWA, J.S.;

OTABBONG E.; LEDIN, S.

Comparison of four low-technology

composting methods for market crop

wastes. Waste Management, v.29,

p.2274-2281, 2009.

TUOMELA, M.; VIKMAN, M.;

HATAKKA, A.; ITÄVAARA, M.

Biodegradation of lignin in a compost: a review. Bioresource Technology, v.72, p.169-183, 2000.

VALENTE, B.S.; XAVIER, E.G.; MORAES, P.DE.O.; MANZKE, N.E.; ROLL, V.F.B. Eficiência do SISCODE e da aeração passiva no tratamento de resíduos da produção animal no município de Capão do Leão/RS.

Revista Engenharia Sanitária e

Ambiental, v.16, n.3, p.231-236, 2011.

ZHANG, Y.; HE, Y. Co-compostig solid swine manure with pine sawdust as organic substrate. Bioresource

Technology, v.97, p.2024-2031, 2006.

ZHU, N. Effect of low initial C/N ratio on aerobic composting of swine manure with rice straw. Bioresource

Technology, v.98, p.9-13, 2007.

Data de recebimento: $26 / 08 / 2015$

Data de aprovação: 25/04/2016 